\title{
A Case of Refractory Henoch-Schönlein Purpura Treated with Thalidomide
}

\author{
Soo Jeong Choi, M.D., Sung Kyu Park, M.D., Wan Sik Uhm, M.D., \\ Dae Sik Hong, M.D., Hee Sook Park, M.D., Young Lip Park, M.D.* \\ and Kye Won Kwon, M.D.
}

\author{
Departments of Internal Medicine, Dermatology* and Pathology ${ }^{*}$, \\ Soonchunhyang University Medical College, Seoul, Korea
}

\begin{abstract}
Henoch-Schönlein purpura is an acute, self-limited vasculitis syndrome which shows characteristic skin, joint, renal and gastrointestinal manifestations. It is common in childhood and may also occur in adults with fatal complications such as nephritis and gastrointestinal bleeding.

We experienced a case of a 20-year-old woman who presented with palpable purpura and severe arthritis. The histopathologic examination of the skin revealed leukocytoclastic vasculitis with perivascular deposition of IgA and she was diagnosed with Henoch-Schönlein purpura. Despite treatment with prednisolone for one month, she had more aggravated purpura and fatal gastrointestinal bleeding. The symptoms were improved shortly by cyclophosphamide pulse therapy with plasmapheresis but symptoms were aggravated and symmetric mononeuropathy of the ulnar nerve developed. She was treated with $400 \mathrm{mg} / \mathrm{day}$ of thalidomide and symptoms were improved. We herein report a case of Henoch-Schönlein purpura successfully treated with thalidomide which was refractory to prednisolone, immunosuppressive drugs and plasmapheresis.
\end{abstract}

Key Words : Henoch-Schönlein purpura, Thalidomide

\section{INTRODUCTION}

Henoch-Schönlein purpura is characterized by palpable purpura, arthritis, nephritis and gastrointestinal involvement. This disease is common in children and runs as a benign, self-limited illness. Adults have more fatal complications, poor prognosis and require more aggressive treatment". Corticosteroids are used in patients with recurrent skin lesions, abdominal pain with gastrointestinal bleeding or nephropathy, and cytotoxic agents are used as corticosteroid-sparing agents. Some cases reported a successful resolution of symptoms refractory to corticosteroid and

Address reprint requests to : Sung Kyu Park, M.D., Ph.D. Assistant Professor of Internal Medicine, Soonchun hyang University Hospital, 1174 Jung-Dong, Wonmi-Ku, Bucheon-City, Gyeonggi-Do, Korea

E-mail : skpark@schbc.ac.kr immunosuppressive drugs using plasmapheresis, immunoglobulin or dapsone. Thalidomide is a promising drug for severe, unusual, dermatologic diseases ${ }^{2}$. Thalidomide has immune modulating effects to reduce cytokine synthesis and to inhibit tumor necrosis factor-alpha synthesis ${ }^{3)}$.

In this report, we describe an adult patient who had refractory Henoch-Schönlein purpura with severe gastrointestinal bleeding, arthritis and peripheral mononeuropathy. The symptoms were refractory to prednisolone, immunosuppressive drugs and plasmapheresis. We applied thalidomide and symptoms were improved.

\section{CASE REPORT}

A 20-year-old woman was admitted to hospital because of arthralgia on both ankles and palpable purpura on both legs for 5 days. Physical examination showed multiple purpura on legs and buttock and 
swelling and tenderness on both elbows and ankles (Figure 1). Laboratory data showed normal blood counts, blood chemistry and urine analysis. C-reactive protein was $3.7 \mathrm{mg} / \mathrm{dL}$ and ESR was $21 \mathrm{~mm} / \mathrm{hr}$. Tests for antinuclear antibody, rheumatoid factor and antineutrophil cytoplasmic antibody (ANCA) were negative. Serum concentrations of immunoglobulin ( $\lg ) \mathrm{G}, \lg \mathrm{A}, \lg \mathrm{M}, \mathrm{C}_{3}$ and $\mathrm{C}_{4}$ were normal. A biopsy specimen of skin lesions showed leukocytoclastic vasculitis and immunofluorescent study revealed IgA depositions on vessels (Figure 2).

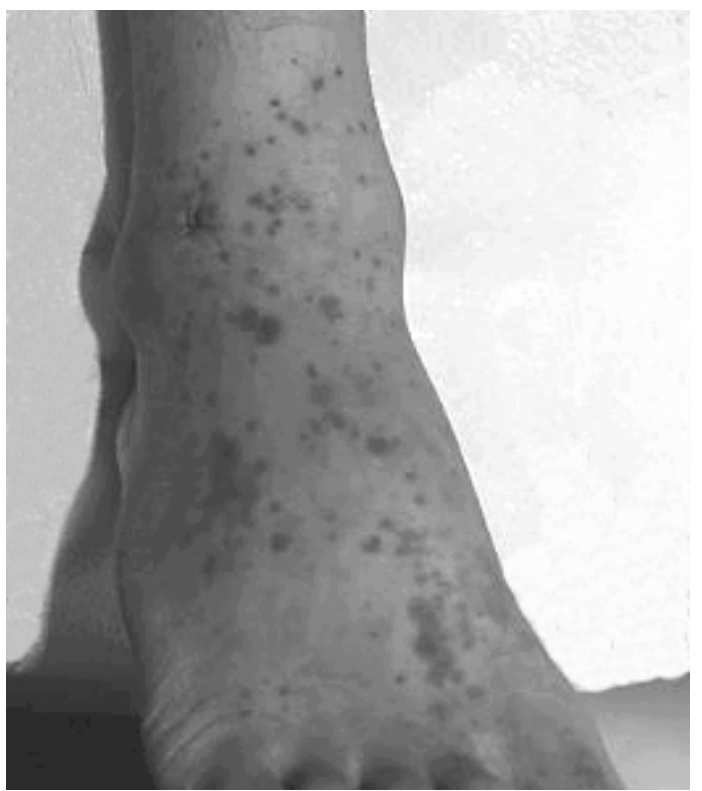

Figure 1. Palpable purpura on the foot.

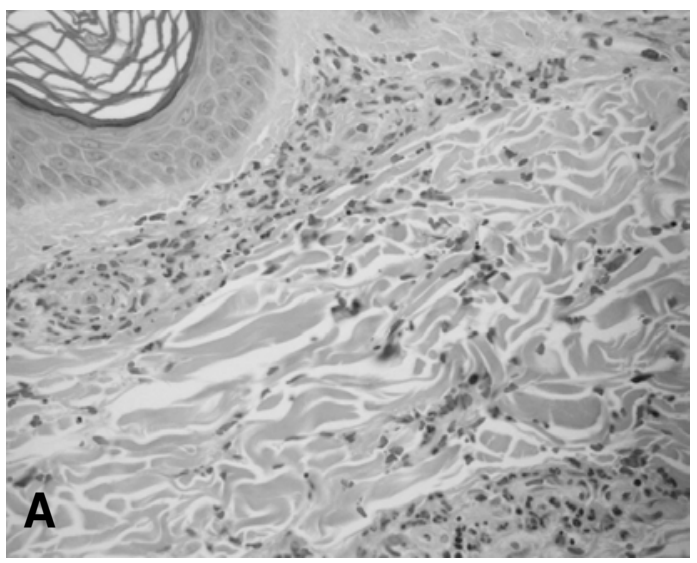

She was treated with prednisolone $50 \mathrm{mg} /$ day $(1 \mathrm{mg} /$ $\mathrm{kg} /$ day) for control of arthralgia which caused the limited motion of both knee joints. Arthralgia was improved immediately but purpura spread to the upper trunk and face and improved slowly one month later. After six weeks, prednisolone was tapered to $20 \mathrm{mg} /$ day. On the seventh week of hospitalization, she experienced abdominal pain and hematochezia and the hemoglobin was decreased to $7.0 \mathrm{~g} / \mathrm{dL}$. Gastrofibroscopic examination revealed hemorrhagic gastritis and colonoscopy revealed multiple ulcerations (Figure 3). Biopsy specimens from the colon showed ulcerations with neutrophils infiltration and fibrin thrombi formation in vessels (Figure 4). Intravenous methyl-prednisolone pulse therapy was not effective for abdominal pain and hematochezia. She was treated with plasmapheresis for 3 days and cyclophosphamide $750 \mathrm{mg}\left(500 \mathrm{mg} / \mathrm{m}^{2}\right)$, followed by prednisolone $30 \mathrm{mg} /$ day. Purpura, arthralgia and hematochezia were much improved and then prednisolone was tapered to $15 \mathrm{mg} /$ day. On the 67 th day of hospitalization, she complained of weakness and numbness of both fourth and fifth fingers, followed by a wrist drop. The study of nerve conduction velocity showed both ulnar nerve mononeuropathy. She was treated with prednisolone $30 \mathrm{mg} /$ day and hydroxychloroquine $200 \mathrm{mg} / \mathrm{day}$ and then the ulnar nerve mononeuropathy, arthralgia and gastrointestinal bleeding resolved but purpura was aggravated. We added $200 \mathrm{mg} /$ day of azathioprine to the patient but it was not effective. Finally, we used $400 \mathrm{mg} /$ day of thalidomide and purpura was improved (Figure 5). After two months of treatment with thalidomide, purpura disappeared and then we tapered thalidomide and stopped.

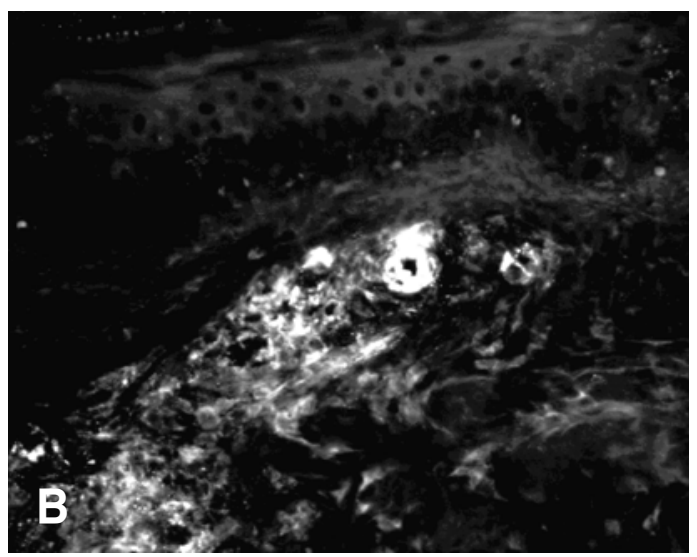

Figure 2. (A) Skin biopsy shows necrotizing leukocytoclastic vasculitis (H\&E, $\times 200)$.

(B) Immunofluorescent examination shows IgA deposition on the wall of vessel. 


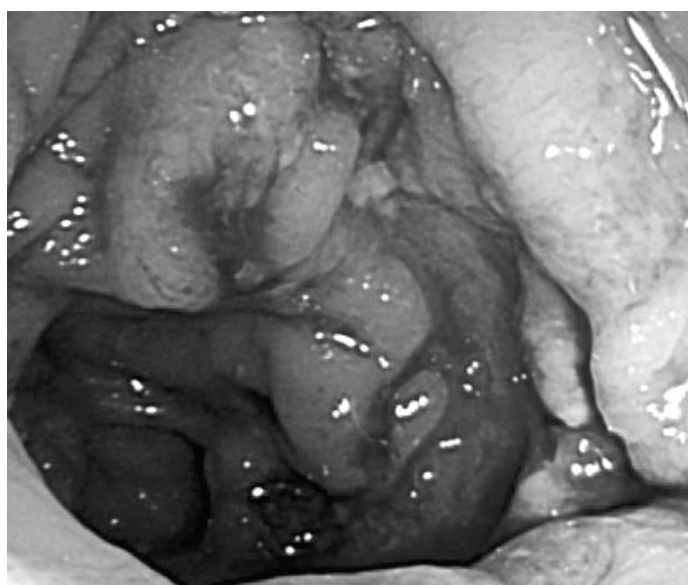

Figure 3. Colonoscopic findings show multiple ulcers with hemorrhage.

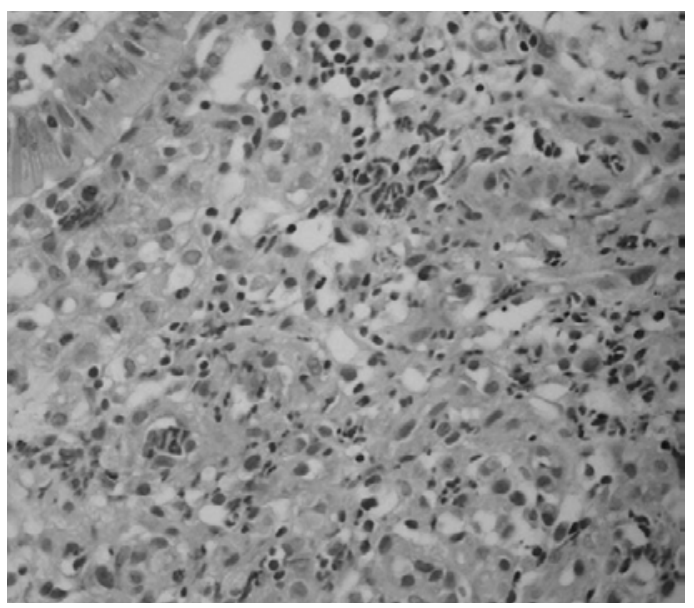

Figure 4. Colon biopsy shows neutrophils and nuclear debris infiltration on the wall of vessels $(H \& E, \times 400)$.

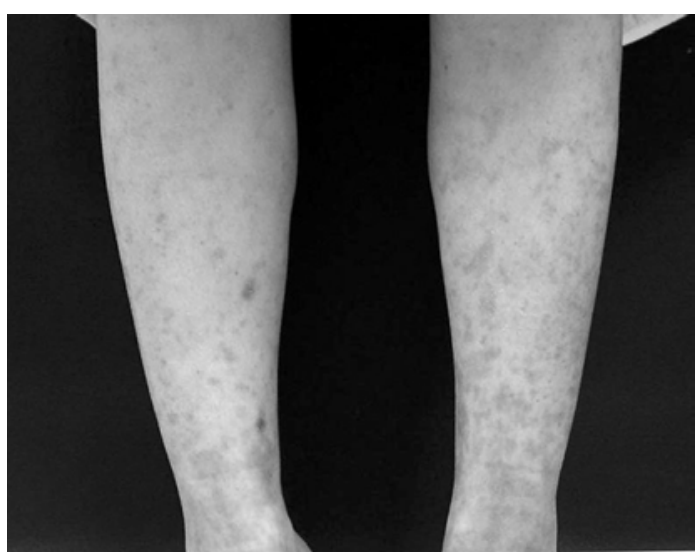

Figure 5. Improved purpura with pigmentation.

\section{DISCUSSION}

Henoch-Schönlein purpura is a systemic vasculitis syndrome that affects small vessels (arterioles and venules) and can present a variety of clinical manifestations. The etiology of Henoch-Schönlein purpura remains unknown, but it is clear that $\lg A$, especially aberrant glycosylated $\operatorname{lgA} 1$, plays a pivotal role in the immunopathogenesis of Henoch-Schönlein purpura"). The diagnosis of Henoch-Schönlein purpura is confirmed by histologic examination of skin biopsy, demonstrating a leukocytoclastic vasculitis with neutrophil infiltration. Immunofluorescent studies reveal granular deposits of $\operatorname{lgA}$ and lesser quantities of C3 and fibrin. This disease is common in children with male dominace (1.5:1). It runs as an acute, benign and self-limited illness that generally lasts about 4 weeks and recurs in $33 \%$ of patients with a mean span time of $2.5 \pm 3.1$ months after initial resolution of symptoms ${ }^{1,5)}$. Nevertheless, Henoch-Schönlein purpura in an adult has more fatal complications and poor prognosis. Adults have more frequent symptoms of joint and renal involvement". Gastrointestinal hemorrhage does not respond to conservative treatment and transfusions and required surgical management ${ }^{6,7}$. Nephritis is one of the manifestations of Henoch-Schönlein purpura that may be chronic and severe. Cardiac and pulmonary complications have been reported and were associated with a poor prognosis ${ }^{8)}$. Neurologic complication occurs in $1 \sim 8 \%$ of patients and includes seizure, confusion, stroke and peripheral mononeuropathy ${ }^{1,9,10)}$.

Abundant clinical experience indicates that corticosteroids are not effective on rash and prevention of recurrences but can control the arthritis and abdominal pain $^{111}$. Other studies have reported the benefit of pulse methyl-prednisolone and cytotoxic agents for nephritis ${ }^{12,13)}$. Cases have been reported with successful resolution of symptoms using plasmapheresis ${ }^{14)}$, immunoglobulins ${ }^{15)}$ and dapsone ${ }^{16)}$.

To date, thalidomide has been used for various severe, unusual, dermatologic disorders' ${ }^{2)}$. The revival of thalidomide began shortly after the drug was withdrawn from the market because of its teratogenic properties. After the therapeutic effects of this were found accidentally in leprosy patients with erythema nodosum leprosum $^{17)}$, thalidomide shows significant clinical impact in several diseases, such as chronic graft-versus-host disease $^{18)}$, systemic lupus erythematosus ${ }^{19)}$ and Behcet's syndrome $^{20)}$. The effects of thalidomide are thought to be 
based on its ability to alter the phenotype of circulating immunological cells, reduce cytokine synthesis and inhibit tumor necrosis factor-alpha synthesis by macrophages. Alteration at the level of cytokine synthesis and release, as well as lymphokine synthesis, changes lymphocyte trafficking and neutrophil migration. Thalidomide alters TNF-a-induced expression of adhesion molecules on endothelial cells and reduces leukocyte extravasation and modulates the response of inflammation ${ }^{3)}$.

In general, Henoch-Schönlein purpura is an acute, self-limited vasculitis, but refractoriness as well as fatal complications are not resolved with conservative treatment. In this case, we tried all therapeutic modalities such as corticosteroids, immunosuppressive agents, hydroxy-chloroquine and plasmapheresis, but the response duration was very short and symptoms aggravated again. We finally tried thalidomide and the symptoms disappeared completely after 2 months. The mechanism of thalidomide to control the symptoms of Henoch-Schönlein purpura is unknown. We suggest that thalidomide modulates immune response and reduces leukocyte extravasation and inflammation by alteration of TNF-a-induced expression of adhesion molecules on endothelial cells and control of the vasculitis of Henoch-Schönlein purpura.

\section{REFERENCES}

1) Saulbury FT. Henöch-Schönlein purpura. Curr Opin Rheumatol 13:35-40, 2001

2) Moraes M, Russo G. Thalidomide and its dermatologic uses. Am J Med Sci 321:321-326, 2001

3) Meierhofer C, Dunzendorfer S, Wiedermann CJ. Theoretical basis for the activity of thalidomide. Biodrugs 15:681-703, 2001

4) Egan CA, Taylor TB, Meyer LJ, Petersen MJ, Zone JJ. IgA1 is the major IgA subclass in cutaneous blood vessels in Henoch-Schönlein purpura. Br J Dermatol 141:859-862, 1999

5) Blanco R, Martinez-Taboada VM, Rodriguez-Valverde V, Garcia-Fluentes M, Gonzalez-Gay MA. Henoch -Schönlein purpura in adulthood and childhood; two different expressions of the same syndrome. Arthritis Rheum 40:859-864, 1997

6) Lippl F, Huber W, Werner M, Nekarda $H$, Berger $H$, Weigert N. Life-threatening gastrointestinal bleeding due to a jejunal lesion of Henoch-Schönlein purpura. Endoscopy 33:811-813, 2001

7) Weber TR, Grosfeld JL, Bergstrein J, Fitzgerald J. Massive gastric hemorrhage: an usual complication of Henoch-Schönlein purpura. J Pediatr Surg 18:576-578, 1983

8) McCarthy R, Rosen T, Chen SH, Raimer SS. Adult Henöch-Schöncein purpura with fatal complications. Arch Dermatol 137:19-21, 2001

9) Belman AL, Leicher CR, Moshe SL, Mezey AP. Neurologic manifestation of Henöch-Schöncein purpura report of three cases and reviews of the literature. Pediatrics 75:687-692, 1985

10) Ritter FJ, Seay AR, Lahey ME. Peripheral mononeuropathy complicating anaphylactoid purpura. J pediatr 103:77-78, 1983

11) Saulsbury FT. Henoch-Schönlein purpura in children; report of 100 patients and review of the literature. Medicine 78:395-409, 1999

12) Oner $A$, Tinaztepe $K$, Erdogan $O$. The effect of triple therapy on rapidly progressive type of Henoch-Schönlein purpura nephritis. Pediatric Nephrol 9:6-10, 1995

13) Lijima K, Ito-Kariya $S$, Nakamura $H$, Yoshikawa $N$. Multiple combined therapy for severe Henoch-Schönlein purpura nephritis in children. Pediatric Nephrol 12:244-248, 1998

14) Kauffmann $\mathrm{RH}$, Houwert DA. Plasmapheresis in rapidly progressive Henoch-Schönlein glomerulonephritis and the effect on circulating immune complexes. Clin Nephrol 16:155-160, 1981

15) Rostoker G, Desvaux-Belghiti D, Pilatte $Y$, Petit-Phar M, Philippon C, Deforges L, Terzidis H, Intrator L, Andre C, Adnot S. Immuno-modulation with low-dose immunoglobins for moderate $\lg A$ nephropathy and Henoch -Schönlein purpura. Nephron 69:327-334, 1995

16) Ledermann JA, Hoffbrand BL. Dapsone in allergic vasculitis; its use in Henoch-Schönlein purpura following vaccination. J $R$ Soc Med 76:613-614, 1983

17) Sheskin J. The treatment of lepra reaction in lepromatous leprosy; fifteen years' experience with thalidomide. Int J Dermatol 19:318-322, 1980

18) Sastry PS, Powles RL. Thalidomide for chronic GVHD. Bone Marrow Transplant 22:933-934, 1998

19) Hawkins DF. Thalidomide for systemic lupus erythematosus. Lancet 339(8800):1057, 1992

20) Jorizzo JL, Schmalstieg FC, Solomon AR Jr, Cavallo T, Taylor RS 3rd, Rudloff HB, Schmalstieg EJ, Daniels JC. Thalidomide effects in Behcet's syndrome and pustular vasculitis. Arch Intern Med 146:878-881, 1986 